\title{
Numerical Simulations of Restrained Shrinkage Cracking in Glass Fibre Reinforced Shotcrete Slabs
}

\author{
Andreas Sjölander and Anders Ansell \\ KTH Royal Institute of Technology, Division of Concrete Structures, 10044 Stockholm, Sweden \\ Correspondence should be addressed to Anders Ansell; anders.ansell@byv.kth.se
}

Received 9 February 2017; Accepted 9 April 2017; Published 3 May 2017

Academic Editor: Peng Zhang

Copyright (C) 2017 Andreas Sjölander and Anders Ansell. This is an open access article distributed under the Creative Commons Attribution License, which permits unrestricted use, distribution, and reproduction in any medium, provided the original work is properly cited.

\begin{abstract}
Modern tunnels in hard rock are usually constructed by drill and blast with the rock reinforced by shotcrete (sprayed concrete) in combination with rock bolts. The irregular rock surface and the projection method of shotcrete lead to a tunnel lining of varying thickness with unevenly distributed stresses that affect the risk of cracking during shrinkage of the young and hardening material. Depending on water conditions, shotcrete is sprayed directly either onto the rock surface or over a drainage system, creating a fully restrained or an end-restrained structural system. In this paper, a method for nonlinear numerical simulations has been demonstrated, for the study of differences in stress build-up and cracking behaviour of restrained shotcrete slabs subjected to shrinkage. Special focus was given to the effects of the irregular shape and varying thickness of the shotcrete. The effects of glass fibre reinforcement and bond were implemented in the study by changing the fracture energy in bending and in the interaction between shotcrete and the substrate. The study verifies that an end-restrained shotcrete slab is prone to shrinkage induced cracking and shows the importance of a continuous bond to avoid wide shrinkage cracks when shotcrete is sprayed directly onto the rock.
\end{abstract}

\section{Introduction}

A common construction method of tunnels in hard and good quality rock is by drill and blast. One way to reinforce the rock is to use wet-sprayed, fibre reinforced shotcrete (FRS) in combination with rock bolts. The shotcrete keeps loose blocks together and ensures the arch shape of the tunnel which enables the rock to carry its own deadweight. Rock bolts are used to secure individual blocks and to provide structural connection between rock and shotcrete where and if the bond strength is insufficient. The thickness of the applied shotcrete will mainly depend on rock surface geometry, the shotcreting process, and the skill of the operator. In the process of spraying, problems with rebound and difficulties in performing accurate measurements lead to variations in thickness of the applied shotcrete. In tunnels and underground caverns, shotcreted linings usually have an outer harmonic shape but, due to the irregular shape of the rock surface, the shotcrete thickness will also become highly irregular. This introduces local stress concentrations, that is, possible locations for crack initiation, as well as variations in temperature and shrinkage. Cracks might be initiated in local thin sections [1], while thicker sections lead to an excessive use of material and higher construction costs. Effects of irregular geometry are usually neglected in the design of shotcrete linings, but research regarding stresses in such tunnel linings shows the importance of considering these effects; see, for example, [24].

Depending on water conditions in the tunnel, the shotcrete can be sprayed either directly on the rock surface or, for example, partly over a system of soft drain mats. For sections with good water conditions, with no large water leading cracks, shotcrete is sprayed directly onto the rock. The bond between shotcrete and rock will restrain movements due to shrinkage and thermal effects. With complete bond between the sections, formations of several small cracks can be expected due to the restrained movement. This was, for example, showed in a test series performed by Malmgren et al. [5] where cracks due to shrinkage were mapped for shotcrete sprayed against a sandblasted concrete wall. Similar results were presented by Carlswärd [6], but here the shrinkage induced cracking of regular cast concrete was studied. 
Groth [7] showed that the distribution and width of the cracks will depend on the bonding and that local debonding leads to severe cracking in that section. However, in none of the experiments above the effects of varying, irregular thickness was considered. For tunnels through sections of infiltrating groundwater, or with high demands on durability, a drainage system must be installed. One solution is to use a system of soft synthetic drain mats which are placed to collect and transport the water to a drainage system. Rock bolts are used to keep the mats in place and the whole system is then covered with shotcrete which will bond to the rock at the end of each section, called bonding zones in this paper. However, the much lower stiffness of the drain mat compared to the shotcrete enables the shotcrete to deform freely between the bonding zones, thus creating an end-restrained slab. In situ mapping and evaluation of a motorway tunnel in Stockholm, Sweden, by Ansell [8] showed extensive shrinkage cracking in shotcrete sprayed on soft drains. Typically, one wide crack appeared in each section, partly due to the strain-softening behaviour of the FRS. Similar behaviour was also found in a test series by Bryne et al. [9] where the end-restrained shrinkage cracking of shotcrete sprayed on soft drains was simulated in laboratory tests. This investigation also involved testing of shotcrete reinforced with glass fibres and evaluation of their effect on delaying and reducing shrinkage cracking. Glass fibres will not be long-term active due to degradation in the alkaline environment inside shotcrete but will be fully effective during the early age, when the risk of shrinkage cracking is at its highest [10]. Addition of many small fibres will distribute stresses within the shotcrete in a way that is not possible with structurally active, fewer, and larger steel fibres. A possible future solution is to combine glass microfibres with steel or synthetic, macrofibres in the shotcrete. The sprayability of such material has also been tested [9].

The aim of this paper is to find a numerical analysis strategy based on the finite element (FE) method, suitable for evaluation of this type of results and for future use in the design process. The model will capture the shrinkage properties of shotcrete and describe the difference in structural behaviour between the two structural systems described, that is, shotcrete fully bonded to rock and with end restraints only. The stress build-up and resulting crack patterns from the analysis model are studied and compared with the in situ results, also including results from testing on shrinking ordinary cast concrete. Special attention is given to the effects from irregular geometry, but the importance of bond strength and partial debonding is also covered but, however, not in the main focus. More studies regarding the influence a varying thickness are presented by Sjölander et al. [10-12].

\section{Materials}

Due to the difficulties in finding accurate material data for shotcrete in the literature, a common but not correct approach is to use material properties of ordinary, cast concrete. The use of different set accelerators and larger cement ratio in shotcrete will affect material parameters such as shrinkage and strength development [13]. Over the last years, the focus on research of material properties and behaviour of young shotcrete has increased; see, for example, Bernard [14], Bryne et al. [15], and Ahmed [16]. The material properties used for the numerical models in this paper were based on the experimental work on young and hardened shotcrete presented by Bryne et al. [15]. For the cast concrete slabs and granite blocks used as substrate in the numerical models, typical material parameters were used. Elastic conditions were assumed, with Young's modulus and Poisson's ratio set to $70 \mathrm{GPa}$ and 0.2 for granite and $35 \mathrm{GPa}$ and 0.2 for concrete, respectively.

2.1. Fibre Reinforced Shotcrete. Typically, FRS shows a strainsoftening behaviour and the type of fibres added to the shotcrete is divided into two categories: macrofibres, sometimes called structural fibres, and microfibres. Macrofibres are used to increase the ductility of shotcrete, while microfibres can be added to, for example, decrease the risk of fire spalling of shotcrete [18] and shrinkage cracking [13]. Microfibres are usually made of glass or synthetic material and an increase of the fracture energy with a factor of 1.1-2.0 could here be expected [19-21]. Macrofibres are of steel or synthetic/plastic material and can increase the fracture energy significantly; see, for example, [22]. The fracture energy obviously depends on amount, type, distribution, and orientation of the fibres in the specimen. A scatter in the results of fracture energy from experiments can therefore be expected. The bond strength between shotcrete and rock mainly depends on the cleanness of the surface and type of rock. Results for normal bond strength are, compared to shear bond strength, commonly found in the literature. However, results for both normal and shear directions, as well as interaction between the two, are rare. A test series presented by Bryne et al. [17] shows that a normal bond strength up to $1.0 \mathrm{MPa}$ can be achieved within 24 hours of curing. This can, for example, be compared with the study by Bernard [14] which shows that a bond strength of only 0.2 MPa was achieved within the first 24 hours. This exemplifies the scatter in results found in the literature and the importance of also considering the type of substrate, curing environment, and material composition. Further examples are given for comparison in Table 1. As a basis for the following numerical examples, material properties from the tests performed by Bryne et al. [15] were used. The development of tensile strength of plain and glass fibre reinforced shotcrete was investigated, with standard four-point bending tests according to EN 14488-3 [23] performed at different time intervals. However, no measurements of the fracture energy were done for the test series that each consisted of three beams sawn out from one sprayed shotcrete slab.

2.2. Material Models. The ductility of the shotcrete material studied here was previously investigated through laboratory testing [15], with four-point loading of standard concrete beams $500 \times 75 \times 125 \mathrm{~mm}^{3}$ (length $\times$ height $\times$ width) [23] Due to the absence of structural reinforcement, the measured postcracking behaviour is captured by a few data points, with the first postcracking point usually found at a displacement of $0.6-0.8 \mathrm{~mm}$ with a corresponding force of $0.4-0.6 \mathrm{kN}$. Due to the few data points from each test, the postcracking softening 
TABLE 1: Compilation of test result for normal and shear bond strength at early age, with $\sigma$ and $\tau$ as the normal and shear bond strengths, respectively.

\begin{tabular}{|c|c|c|c|c|c|}
\hline Reference & Surface & Material & Test conditions & $\sigma(\mathrm{MPa})$ & $\tau(\mathrm{MPa})$ \\
\hline Bernard [14] & Various & Shotcrete & In situ & 0.2 & - \\
\hline Hahn [29] & Granite & Shotcrete & Laboratory & $0.3-1.7$ & - \\
\hline Silfwerbrand [28] & Concrete & Shotcrete & In situ & 0.38 & 2.85 \\
\hline Saiang et al. [30] & Magnetite and trachyte & Shotcrete & Laboratory & 0.56 & 0.50 \\
\hline Ellison [31] & Granite & Shotcrete & In situ & 1.37 & - \\
\hline Bryne et al. [17] ${ }^{2}$ & Granite & Shotcrete & Laboratory & 1.50 & - \\
\hline Silfwerbrand [28] & Concrete & Shotcrete & Laboratory & 1.72 & 3.35 \\
\hline Moradian et al. [32] $]^{1}$ & Barre granite & Concrete & Laboratory & - & 4.79 \\
\hline
\end{tabular}

${ }^{1}$ Results are mean values from presented results with a bonding of $100 \%$.

${ }^{2}$ Results are mean values after three days of curing.

TABle 2: Material parameters for the damage plasticity model. See Figure 1 for explanation of material parameters.

\begin{tabular}{lcccccccccc}
\hline Shotcrete & Slab & $F_{\mathrm{cr}}(\mathrm{kN})$ & $\delta_{\mathrm{cr}}(\mathrm{mm})$ & $E(\mathrm{GPa})$ & $\sigma_{t}(\mathrm{MPa})$ & $G_{f}(\mathrm{Nm})$ & $\sigma_{1}(\mathrm{MPa})$ & $\sigma_{2}(\mathrm{MPa})$ & $w_{1}(\mathrm{~mm})$ & $w_{2}(\mathrm{~mm})$ \\
\hline Plain, 7 days & $1^{*}-2$ & 8.75 & 0.14 & 31 & 3.64 & 125 & 0.036 & - & 0.08 & - \\
$5 \mathrm{~kg} / \mathrm{m}^{3}, 7$ days & 3 & 7.55 & 0.15 & 29 & 2.64 & 139 & 0.317 & 0.0264 & 0.06 & 0.32 \\
$5 \mathrm{~kg} / \mathrm{m}^{3}, 14$ days & $4^{*}$ & 6.31 & 0.14 & 29 & 2.00 & 139 & 0.240 & 0.0200 & 0.09 & 0.40 \\
$10 \mathrm{~kg} / \mathrm{m}^{3}, 7$ days & $5^{*}-6$ & 9.00 & 0.15 & 29 & 3.48 & 147 & 0.522 & 0.0348 & 0.05 & 0.21 \\
\hline
\end{tabular}

* Analysed using FE modelling.

behaviours for plain and glass fibre reinforced shotcrete were therefore assumed here as linear and bilinear, respectively. These basic strain-softening curves, as proposed by, for example, [24, 25] and shown in Figure 1, have been used here as input to a finite element (FE) model of the test beams, in order to verify the material model behaviour for the following numerical studies. A beam model with fully integrated 2D plain strain elements, C3PS in the analysis program Abaqus [26], was used, with the mesh size set to $5 \mathrm{~mm}$ and with a prescribed displacement used as load. The results are shown in Figure 2, plotted together with the corresponding loaddisplacement curves from the laboratory tests. The material parameters used for modelling this tensile behaviour with the damage plasticity material model in Abaqus are given in Table 2 . The relation between fracture energy $G_{f}$, crack width $w$, and tensile stress $\sigma_{t}$ is for the linear case given by

$$
G_{f}=\frac{\left(\sigma_{t}-\sigma_{1}\right) w_{1}}{2}
$$

and in the case of the bilinear softening given by

$$
G_{f}=\frac{\sigma_{t} w_{1}+\sigma_{1} w_{2}-\sigma_{2}\left(w_{1}+w_{2}\right)}{2} .
$$

The minimum stress in each case above, that is, $\sigma_{1}$ and $\sigma_{2}$ for (1) and (2), respectively, was limited to $\sigma_{t} / 100$ to avoid numerical problems. Values for plain, unreinforced shotcrete and versions with a different amount of glass fibres added are given. For each of the four types included, the material parameters are valid for 7 or 14 days of age, corresponding to times of failure for tested shotcrete slabs; see [15] and the presentation in the following sections.
An important part of the modelling of the shotcrete behaviour is to find an accurate model for the material interaction at the interface between shotcrete and substrate. For each model, the interaction between the structural elements at the interface was modelled in four different ways (A-D), to investigate the influence and importance of debonding. The interaction was modelled using a master-slave surface interaction and, for model $\mathrm{A}$, an elastic criterion was used which enforces all movements from the master surface to the slave surface during the analyses. A damage-based behaviour was implemented for models B-D, based on a stiff elastic behaviour between the two surfaces up to a critical stress level [26]. The stiffness of the surfaces is calculated based on a maximum slip between the master and slave nodes of $0.5 \%$ before damage is initiated. The critical normal and shear bond stresses were set to 1.5 and $3.0 \mathrm{MPa}$, respectively, which is in agreement with results presented in Table 1. The failure criterion was defined based on a single stress parameter; that is, the interaction between normal and shear stress with respect of failure was not considered. The damage evolution was based on fracture energy with linear softening, as described in Figure 1. The critical nodal displacement $w_{b}$, at which full debonding occurs, is based on the relation between fracture energy $G_{b}$ and critical tensile stress $\sigma_{b}$, according to

$$
G_{b}=\frac{\sigma_{b} w_{b}}{2}
$$

following the same formulation as in (1). The fracture energy for debonding in the normal direction according to models $\mathrm{B}-\mathrm{D}$ was set to 125,40 , and $10 \mathrm{Nm}$, which corresponds to a nodal displacement in the normal direction of $0.167,0.05$, and $0.01 \mathrm{~mm}$, respectively. 

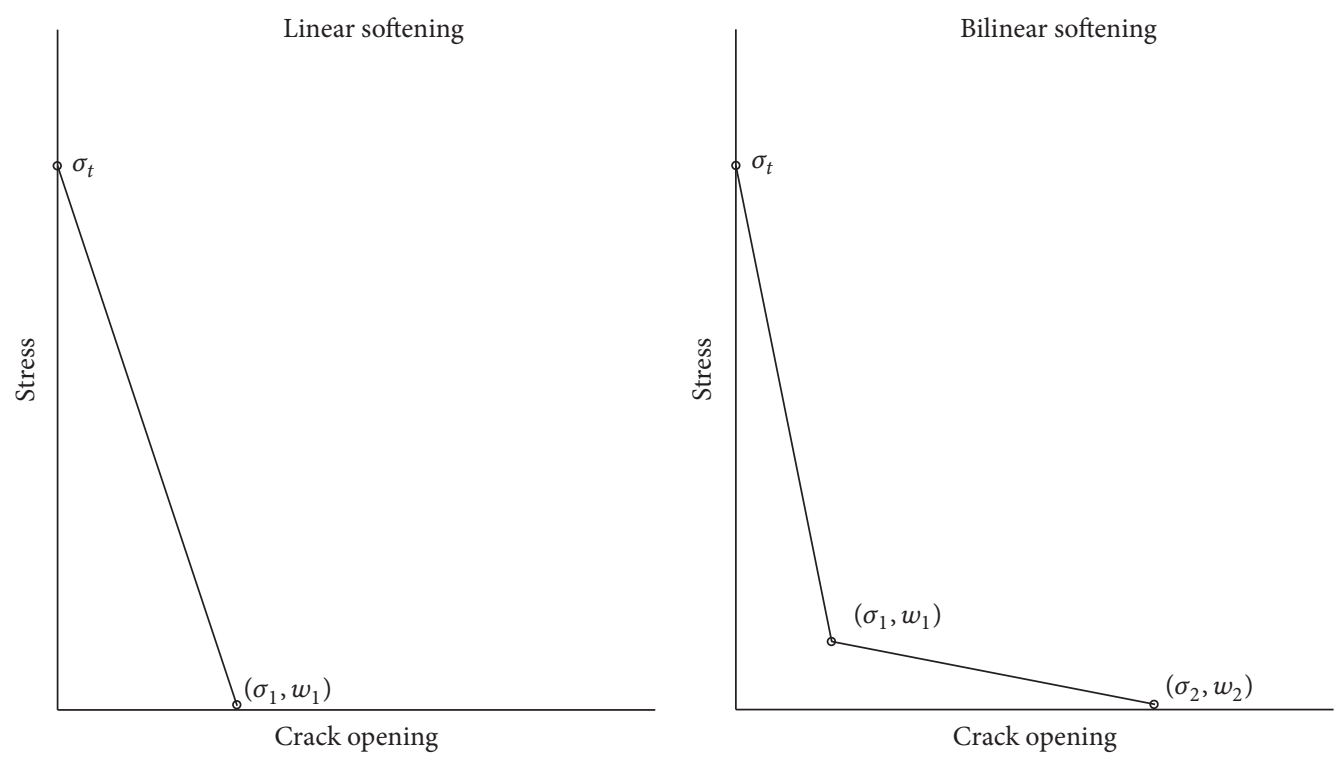

FIGURE 1: Schematic view of linear and bilinear strain softening.
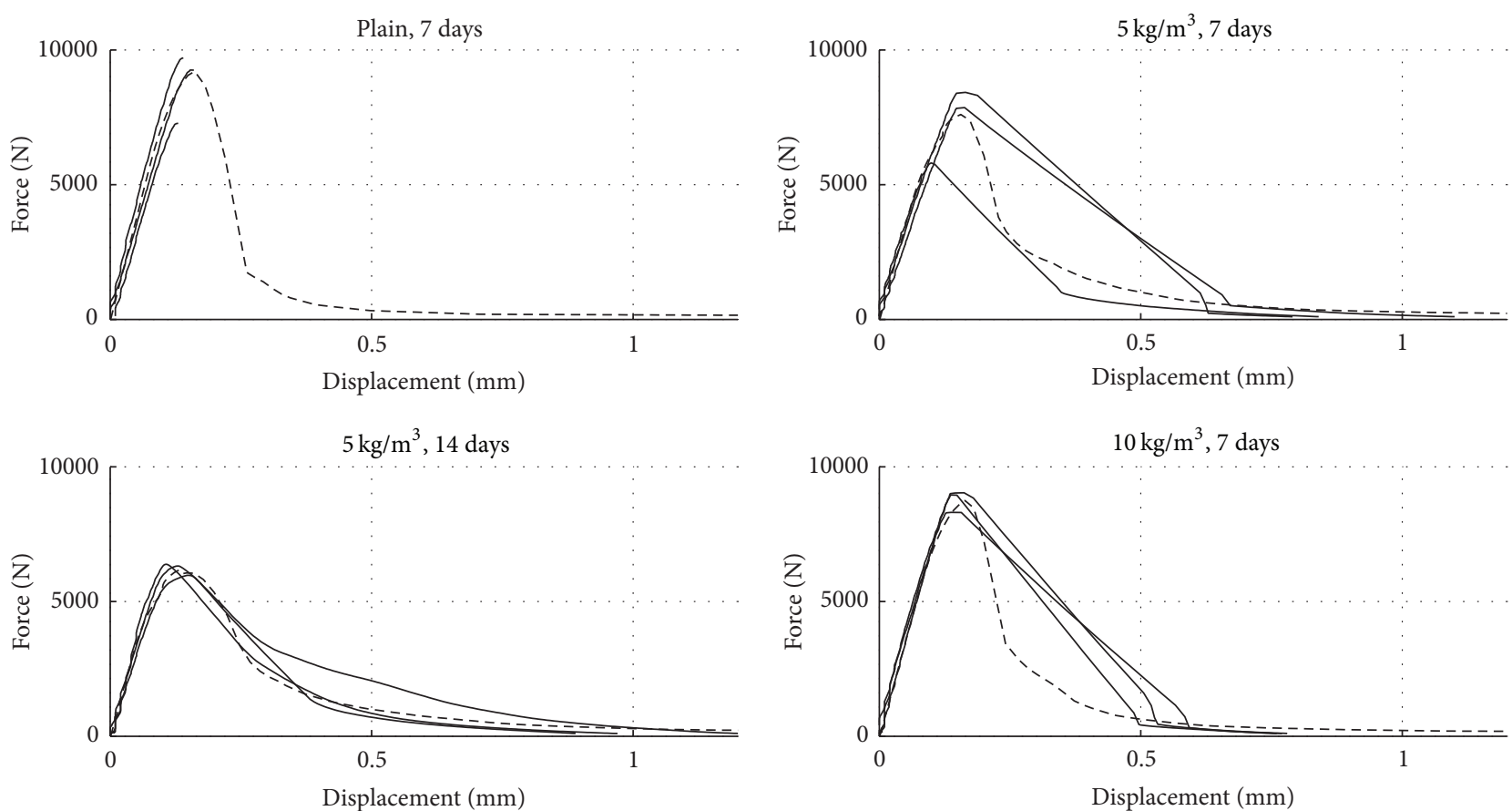

Test results

_. - FEM

FIgURE 2: Force-displacement curves from experimental tests [15] and numerical analyses.

\section{Methods}

Two cases are studied in the following, the first with the aim to verify the behaviour of the material model used for shrinking concrete and shotcrete and the second to assess previously conducted laboratory tests with shrinking shotcrete slabs. For the numerical simulations, the FE software Abaqus [26] was used also in this case, with the nonlinear behaviour of plain and fibre reinforced shotcrete governed by a concrete damage plasticity model. The material parameters given in Table 2 were used, describing the same materials as was tested by the previously presented $2 \mathrm{D}$ beam model. The effects of the fibre reinforcement were here accounted for through an increase of the fracture energy. The bond between the shrinking overlay and the substrate, which, for the two cases, are concrete and granite, is modelled as described in the 
previous section, using four different approaches that will be compared in the following examples. The deformation properties of the substrates are assumed to correspond to a linear material behaviour. For the analyses, 3D models were created using brick elements of type C3D8R, with linear and reduced integration. An implicit solver was used and the error tolerance for equilibrium was set to $5 \%$. For the substrate materials, coarser meshes could be used and all translations of the lower surfaces were restricted. The analyses of the effects due to differences in restrained movement and irregular thickness focus on the crack distribution and the shrinkage over the shotcrete cross section was therefore considered as a uniformly distributed field. The aim was not to fully reproduce the experimental results but to compare results from the evaluation of the structural behaviour. The development of material properties with shotcrete age has not been incorporated into the model and instead the material properties are chosen as valid at the age of cracking, as observed during testing and here given in Table 2.

3.1. Shrinkage Cracking of Concrete Beams. The first case studied is based on experiments performed with concrete beams cast on a concrete substrate. The aim is here to verify the model behaviour through comparison with detailed results demonstrating cracking and debonding for fully and partially restrained test specimens. Since such laboratory results for shotcrete are missing, the test series by Carlswärd [6] were here used, although performed with cast concrete. The concrete used has properties that are slightly different from the description given in the previous sections, but here the focus is on the principal behaviour of the FE model and location of the shrinkage cracks that appear. The thickness of the concrete overlays is representative for the required shotcrete thickness for tunnels in rock with good quality. In the test series, a number of plain, fibre reinforced and steel bar reinforced concrete beams was cast on concrete slabs with different surface treatment, of which results for four plain unreinforced beams are used here. The dimensions of the test beams were $2500 \times 150 \times 50 \mathrm{~mm}^{3}$ (length $\times$ width $\times$ height), as shown in Figure 3. Here are also indicated areas with no bond between beams and substrate, which was incorporated for some of the test beams to simulate the effect of partial loss of bond. Shrinkage strains in the beams were measured and crack patterns and debonded areas were mapped during a period of over 100 days of concrete shrinkage. The strains and stresses measured during testing corresponded to a free shrinkage of around $600 \mu \varepsilon$, but large variations in strain between upper and lower surface due to the one-sided drying condition were observed. For further details on the experimental setup, see [6]. For the FE analysis of shrinkage cracking of the fully restrained and partially debonded beams, the material model corresponding to plain shotcrete in Table 2 was used. The FE mesh was generated with a global mesh size of $15 \mathrm{~mm}$ and the shrinkage was applied as an equivalent, linearly increasing and uniformly distributed temperature field, here up to $500 \mu \varepsilon$. The expansion bolts used in the experimental setup were considered by using a tie command for one row of elements between the beam and slab. The different cases of partial debonding indicated in
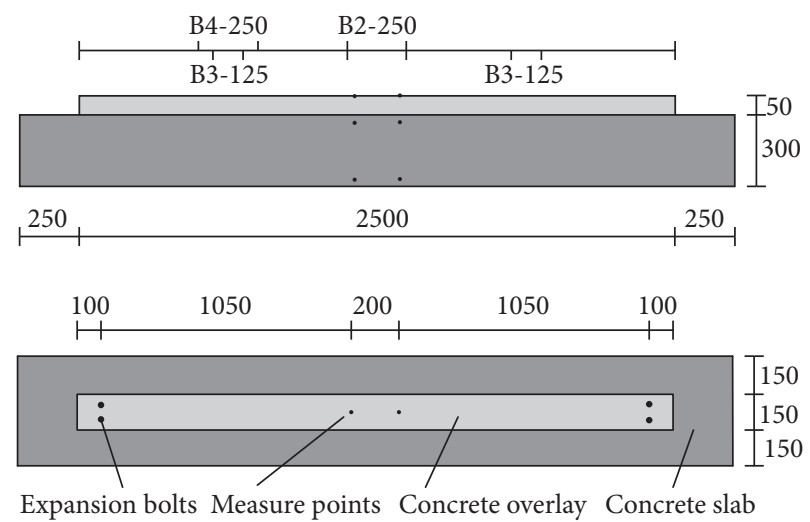

FIGURE 3: Vertical and horizontal view of test setup for shrinkage cracking testing for plain concrete beams [6]. For beams B2, B3, and B4, positions and length of initial debonding are shown. Measurements are in $\mathrm{mm}$.

TABLE 3: Amount of glass fibre reinforcement, time at failure due to shrinkage, and measured thickness for slabs 1-6 tested by Bryne et al. [17]. Slabs S1, S4, and S5 are here analysed using FE modelling.

\begin{tabular}{lccccc}
\hline \multirow{2}{*}{ Slab } & Fibre content $\left(\mathrm{kg} / \mathrm{m}^{3}\right)$ & \multirow{2}{*}{ Failure (days) } & \multicolumn{3}{c}{ Thickness $(\mathrm{mm})$} \\
& & & Min & Max & Mean \\
\hline $\mathrm{S}^{*}$ & 0 & 6 & 12 & 38 & 25 \\
$\mathrm{~S} 2$ & 0 & 7 & 21 & 45 & 33 \\
$\mathrm{~S} 3$ & 5 & 6 & 19 & 48 & 32 \\
$\mathrm{~S} 4{ }^{*}$ & 5 & 14 & 25 & 45 & 37 \\
$\mathrm{~S}^{*}$ & 10 & 7 & 20 & 58 & 37 \\
$\mathrm{~S} 6$ & 10 & 6 & 17 & 57 & 41 \\
\hline
\end{tabular}

${ }^{*}$ Analysed using FE modelling.

Figure 3 were set at the start of analysis, depending on which test beam was studied.

3.2. Shotcrete Slab Shrinkage. The second case consists of a test series of shotcrete slabs sprayed on simply supported granite blocks [17] $1100 \times 400 \times 100 \mathrm{~mm}^{3}$ (length $\times$ width $\times$ height), instrumented with strain gauges to record bending strains. The aim with this setup was to represent an in situ case in which synthetic mats are used to drain infiltrating water. The drainage system and the corresponding experimental setup are shown in Figure 4. The thickness of the slabs was considered to be uniform and the granite to be crack-free and without other imperfections. Two layers of plastic sheet were placed over a $700 \times 400 \mathrm{~mm}^{2}$ centre area of the slabs prior to shotcreting, to simulate the effect of shotcrete sprayed on soft drain mats. This created an area of free horizontal movement for the shotcrete sprayed over the plastic film and granite slab, only bonding to the granite block over an area of 200 $\times 400 \mathrm{~mm}^{2}$ at each end. Six slabs, S1-S6, were sprayed and monitored in a laboratory environment. The slab thickness, glass fibre content, and time at first shrinkage crack appearance are shown in Table 3. The thickness of the shotcrete slabs between the bonding zones was measured using a mechanical profile measuring device over a basic grid pattern of $50 \times$ $10 \mathrm{~mm}^{2}$. In the vicinity of the cracks, a denser grid pattern 


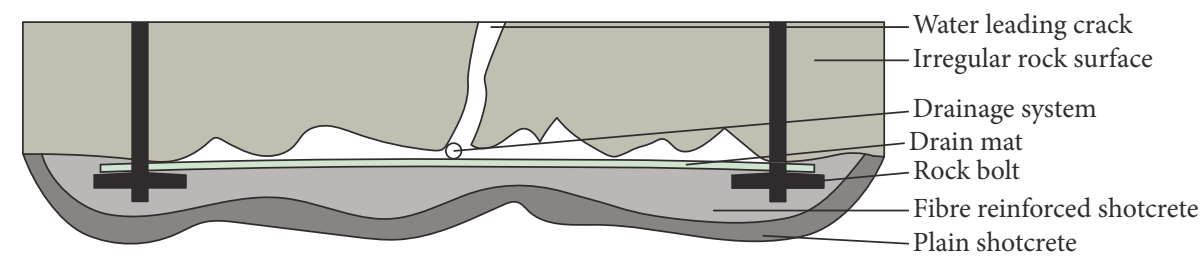

(a)

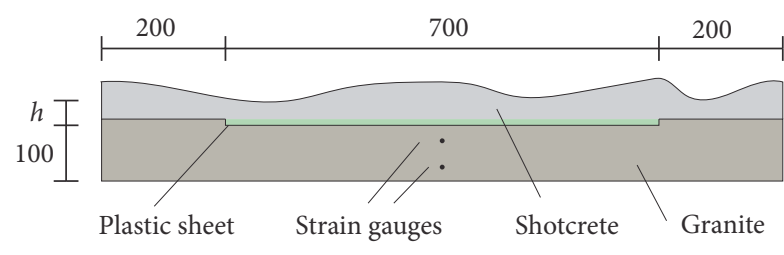

(b)

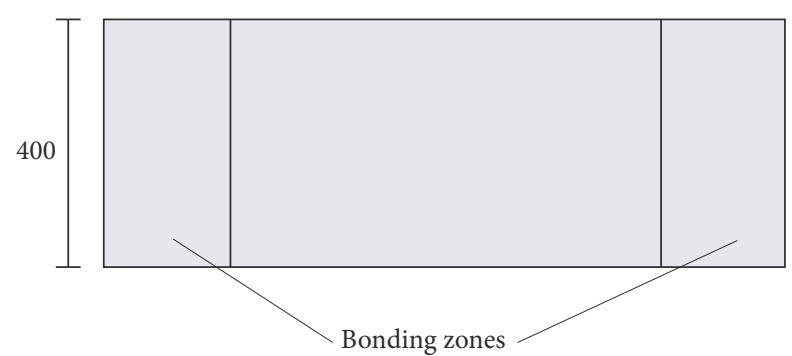

FIGURE 4: (a) shows the in situ principle of a drainage system with synthetic drain mats. (b) shows test setup for shrinkage cracking testing [17] of shotcrete slabs with varying thickness. Vertical and horizontal view. Measurements in (mm).

of $10 \times 10 \mathrm{~mm}^{2}$ was used. The measured strain in this case corresponded to a free shrinkage of approximately $200 \mu \varepsilon$. For further details on the testing procedure and results, see $[9,15,17]$. To capture the measured irregularities, that is, the topography, of the slabs in the FE model, a global mesh size of $5 \mathrm{~mm}$ was used. A point cloud for the upper surface of each slab was created from the measured thickness and linear interpolation between measured points was used to make this cloud denser. The lower surface of the shotcrete slab which was in contact with the plastic sheet was however considered to be perfectly flat. With the use of the software HyperMesh [27], the two point clouds were merged into a solid element mesh. Numerical analyses of three of the six end-restrained slabs are presented here, with full bond between shotcrete and granite assumed at the end areas only. For comparison was also a case with fully restrained shrinkage performed with this setup, simulating the absence of the plastic sheet before spraying and thus full bond to the granite. Here, also the four formulations $\mathrm{A}-\mathrm{D}$ for the bond interface interaction were tested. Also for these FE models, the shrinkage was applied as an equivalent, uniformly distributed temperature field, here up to $200 \mu \varepsilon$ for the end-restrained case and to $2000 \mu \varepsilon$ for the fully bonded case.

\section{Results and Discussion}

The following two sections present the FE results from the analyses of the shrinking concrete beams and shotcrete slabs. When discussing the results, the term "damage initiation" will be used when plastic strains have formed and "crack" is used for crack widths over $0.05 \mathrm{~mm}$.

4.1. Shrinkage Cracking of Concrete Beams. Experimental and numerical results based on the concrete beam model and laboratory tests are presented and compared in Figure 5. Because different material properties were used in the numerical simulations compared with the ones in the experiments, a detailed comparison with respect to crack widths will not be fully accurate. The overall structural behaviour of the experiments was however captured by the numerical simulations, with respect to debonding and crack patterns. It should be noted that, in the simulations, debonding was set at the start of the analysis while it, in the experiments, occurred during the monitoring. It can be seen that the numerical simulations resulted in only thin cracks in the fully restrained beam in Figure 5(a) and that narrow cracks appeared for the beams with partial debonding in Figures 5(b)-5(d). The experimentally obtained crack widths were thus larger than those obtained in the numerical simulations, indicating a stiffer behaviour in the numerical analyses. Possibly, one cause of the stiffer behaviour can be the differences between the shotcrete material properties used in the simulations and that of the concrete used in the experiments [6]. Another possible explanation is the use of the concrete damage plasticity model implemented in Abaqus [26]. This model is based on damage localization in one element, with a subsequent stiffness-degradation, which implies that the fracture process zone of the shotcrete becomes equal to the mesh size in the numerical model. In reality, the fracture process zone and hence the softening will be localized to a larger area which is neglected in the model. It is also possible that the tensile stresses were underestimated since the effects of nonlinear shrinkage, that is, the effects of one-sided drying, here were approximated with a uniform shrinkage. This will cause a strain gradient over the thickness [6] and therefore possibly introduce a bending moment in the beams. However, the results from this model verify in general the structural behaviour of the fully restrained and partially debonded beams. Comparison with the results from [6] clearly shows a correlation between debonding and formation of wide cracks, which thus can be captured by the model. 


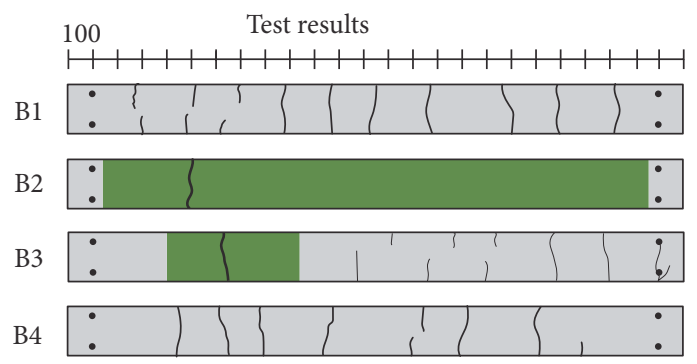

Concrete/shotcrete

Debonding prior analysis

Debonding during analysis

(a)

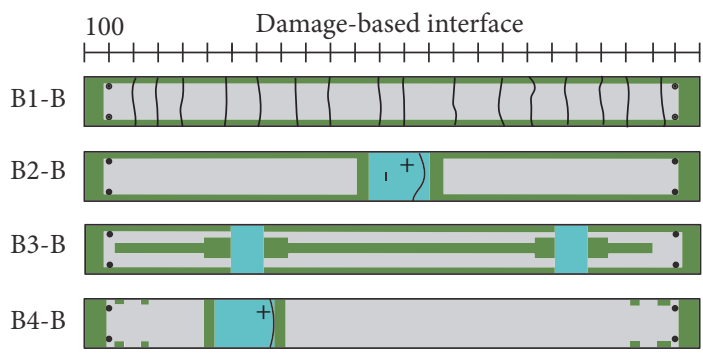

(c)
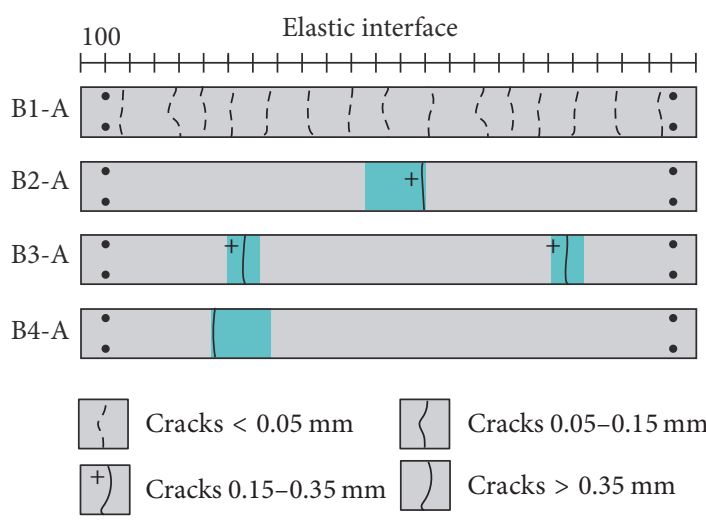

(b)

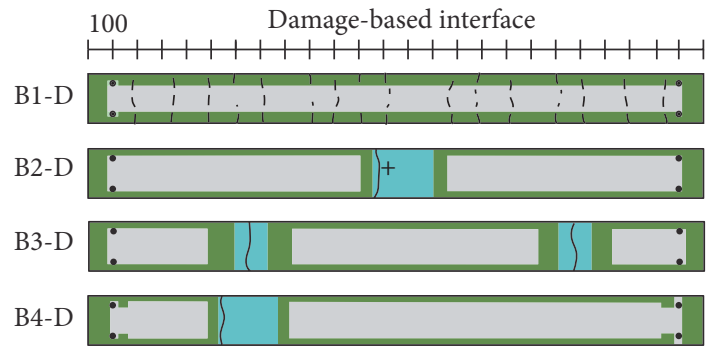

(d)

FIGURE 5: Crack patterns for thin beams B1-B4 cast on concrete slabs, (a) experimental results from [6], (b) numerical simulations with elastic interaction, (c) numerical simulations with $G_{f}=125 \mathrm{Nm}$, and (d) numerical simulations with $G_{f}=10 \mathrm{Nm}$. Measurements in (mm).

4.2. Shotcrete Slab Shrinkage. The results from analysis of the shotcrete slabs with varying, irregular thickness are presented in Figure 6, showing results for three of the six slabs tested: S1, S4, and S5. The parts of the slabs shown are the middle parts that are unrestrained from the substrate; that is, the outer areas bonded to and providing anchorage with the granite are not shown. As a comparison, the numerically obtained cracks are shown together with the results from the laboratory tests by Bryne et al. [15]. The cracks are marked with solid and dashed lines for the experimental and numerical results, respectively. As can be seen from the topographical plots (left side), each of the presented slabs only shows one shrinkage crack across the width. During testing, these cracks appeared close to the centre section of the slabs, as theoretically would be the case for a perfect shotcrete slab with even thickness. However, it can be seen here that the cracks adapt to the surrounding topography.

This is also the case for the theoretically obtained cracks, but these tend to be positioned along paths with thinner slab dimensions, which is most striking in slab S4. The sectional plots (right side) show the slab thickness along the cracks, in comparison with the maximum and minimum thickness in all sections across the width of the slabs. For all three slabs, the theoretically obtained (FEM) curves are slightly closer to the minimum curve than are the test curves. However, for slab S4, the difference is greater, indicating that effects, such as variation in ballast and fibre distribution, or spraying defects, may have influenced the initiation of the crack during testing. It should be noted that, for shotcrete slabs with end restraints only, all the shrinkage deformation will occur at the first opened macrocrack, leading to a full separation of the two parts of the slab, but possibly with some fibres bridging the crack. The numerical analysis and the tests showed that this happened for an average shrinkage strain of around $200 \mu \varepsilon$ for all slabs. When comparing the results from slab S4 with that for S1 and S5, it should be noted that the former was older at time of cracking during testing, 14 days compared with 6 and 7 days, respectively. Slab S4 also had slightly different material properties compared with the others, as can be seen from Tables 2 and 3. No other effect from the glass fibre reinforcement could be concluded from this comparison.

Numerical analysis (FEM) results for slabs S1, S4, and S5 with assumed full bond to the subsurface granite are also presented as a comparison. The results in Figure 7 are organized as in Figure 6, with topographical and sectional plots. To simplify comparison, only the $700 \mathrm{~mm}$ long centre parts are shown also for this case. It should here be noted that all four models (A-D) for the shotcrete bond were tested during modelling, but all variations for each slab resulted in close to identical results. A comparison with Figure 6 shows that the major difference is that multiple cracks appear in this case, with only a few of the cracks crossing the entire widths of the slabs. There are relatively many edge-cracks with a length of $100 \mathrm{~mm}$ or less. It should be noted that most 

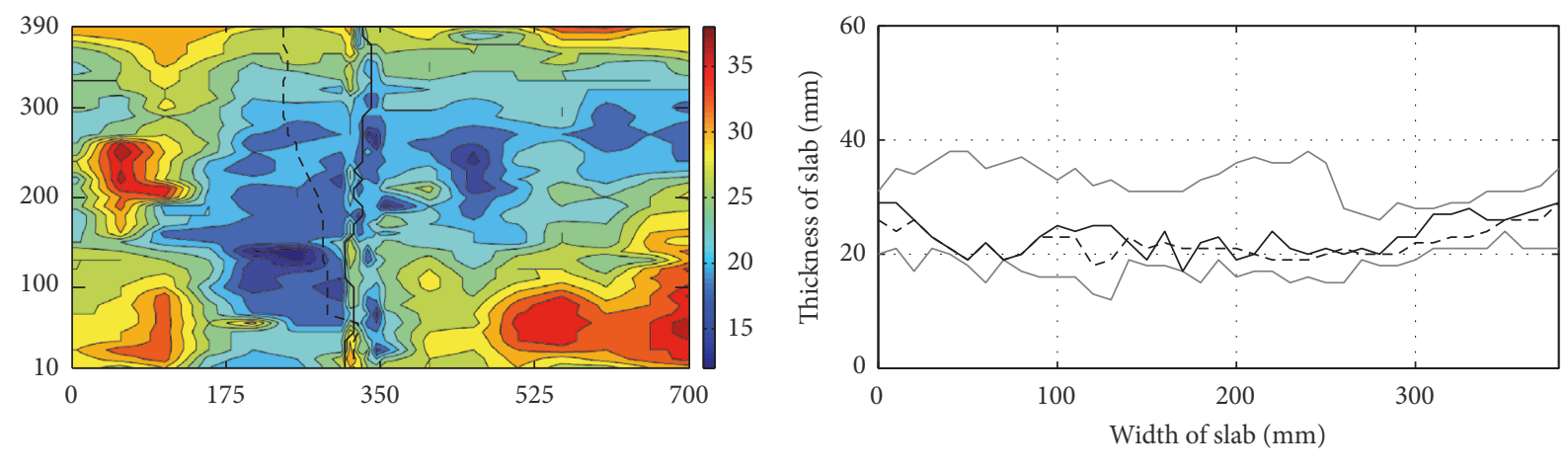

_ Max/min slab thickness
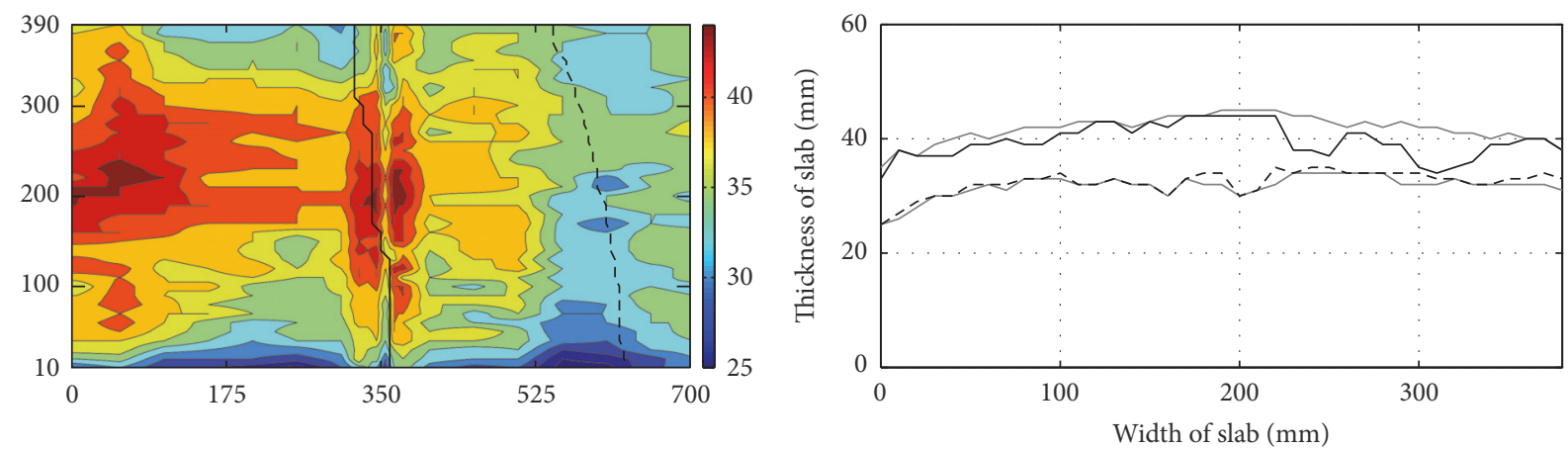

Max/min slab thickness
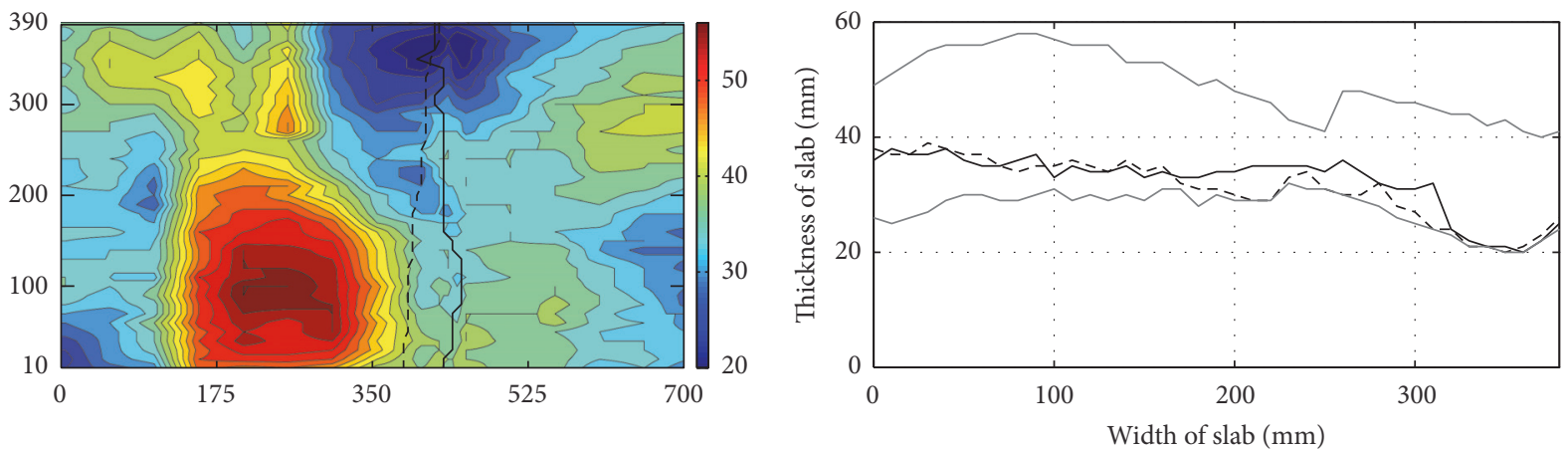

FiguRE 6: Topographical and sectional plots with crack patterns for end-restrained slabs S1, S4, and S5 (top to bottom). Solid lines show experimental results from [15] and dashed lines numerical result. All measurements in (mm).

of the cracks here are surface cracks, due to the bond to the subsurface. This means that the sections of the slabs did not separate as in the end-restrained slabs in the previous case. Also, the development of a macrocrack is here not as distinct as in the previous case, with a more gradual crack opening. Due to this, shrinkage strains up to $2000 \mu \varepsilon$ were applied during this analysis in order to find all major cracks that will develop into macrocracks. For the thinnest slab S1, there are multiple edge-cracks that only extend some $50 \mathrm{~mm}$ into the slab, as can be clearly seen in the sectional plot (right side) in Figure 7. It is evident that these distributed cracks in an effective way contribute to stress relaxation and prevention of further major cracking. This crack pattern is in good correspondence with observations in situ, as shown in, for example, [8], and during laboratory testing, as shown in [6] and [28]. The shear stresses for a fully restrained slab, or beam, will be at its maximum around the slab perimeter and the debonding will therefore start from the outer edges of the bonded area and move towards the centre. The slab S4 also shows edge-cracks, which are, however, longer and only at the centre section. A comparison with the results in Figure 6 shows a crack from testing in the same position but with the crack from the corresponding numerical analysis further to the right and over a thinner section of the slab. As previously discussed, the different behaviour of slab S4 may be due to differences in material properties. The best example of crack distribution is here demonstrated by the relatively thick slab S5, with edge-cracks, one crack crossing over the entire width, and also with cracks along the length of the slab. Indications of the latter can also be seen on slab S1, but not on S4. For slab S5, it should specially be noted how the crack pattern distributes around areas with larger thickness. 

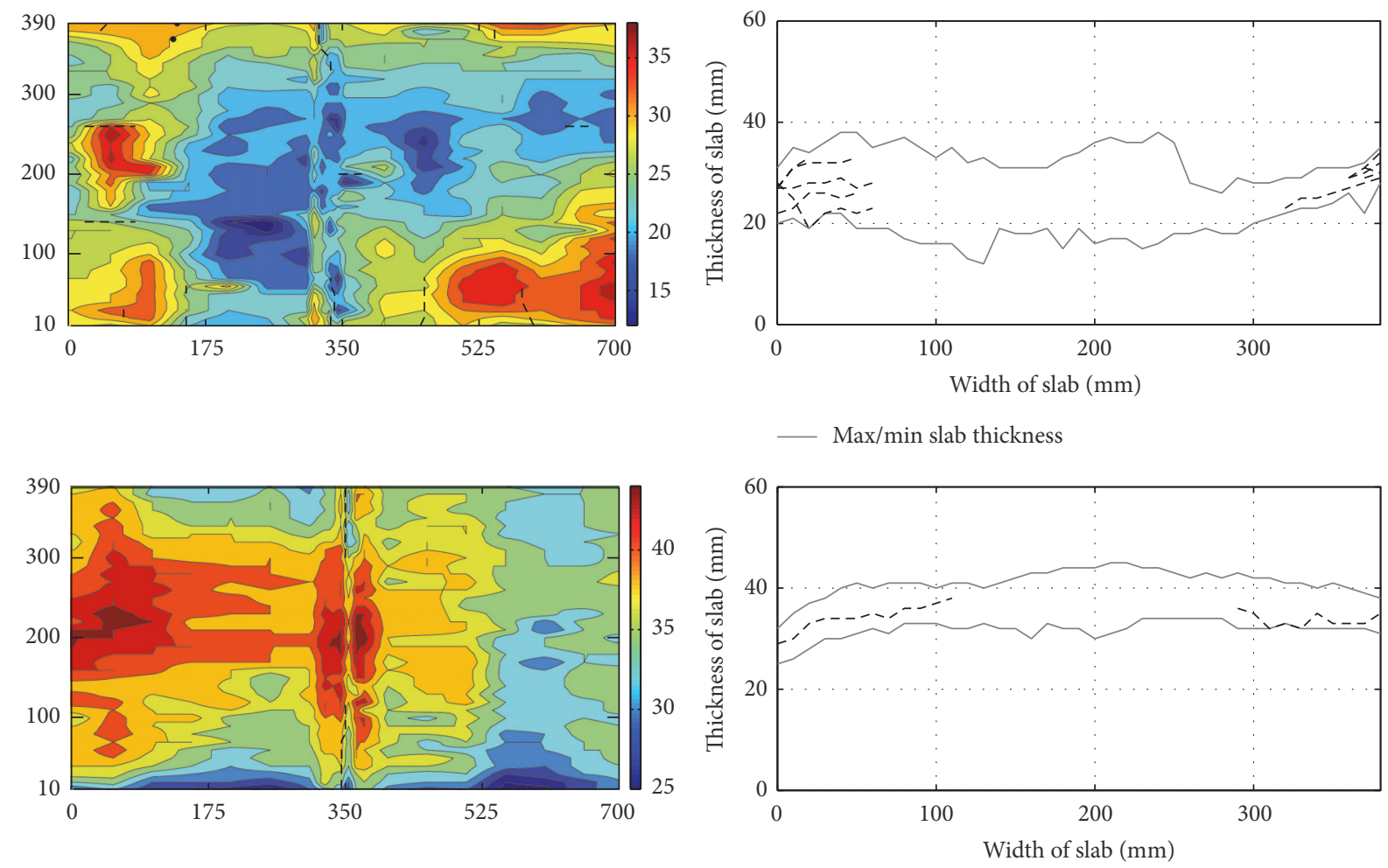

_ Max/min slab thickness
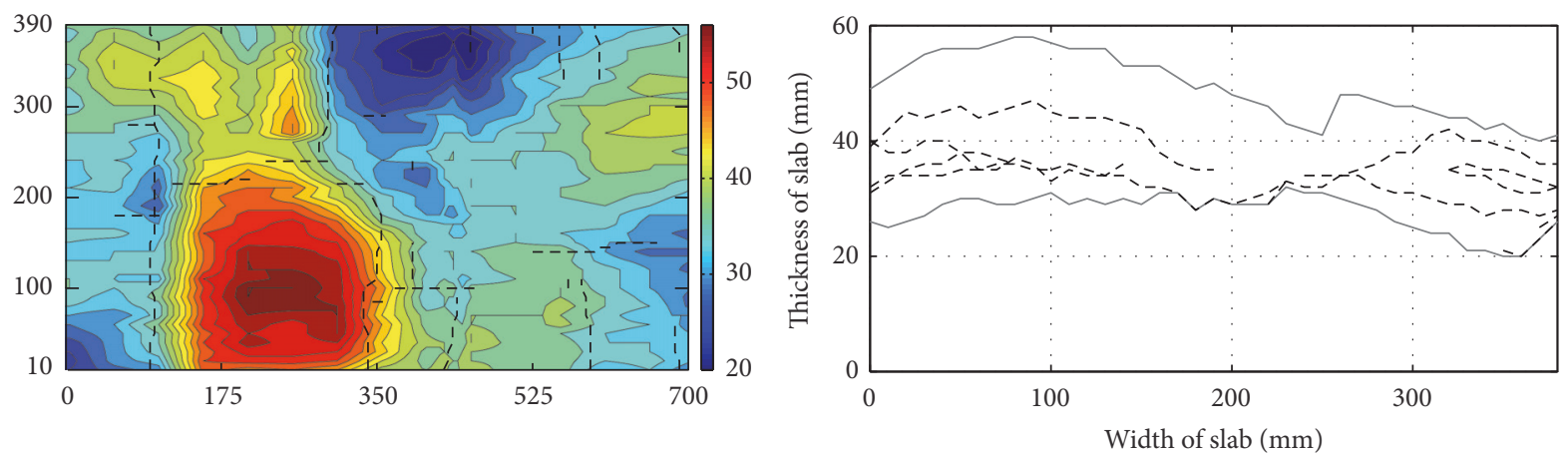

FIGURE 7: Topographical and sectional plots with crack patterns from numerical analysis of fully bond-restrained slabs S1, S4, and S5 (top to bottom). All measurements in ( $\mathrm{mm})$.

\section{Conclusions}

A numerical analysis strategy based on the finite element (FE) method has been presented and demonstrated through examples and comparisons to be suitable for describing restrained shrinkage cracking in shotcrete slabs. The analytical model can describe the difference in structural behaviour between the two structural systems constituted by shotcrete fully bonded to rock and with end restraints only, the latter being represented by shotcrete covered soft drains. Of importance is that the irregular shape and varying thickness of a shotcrete lining can be accurately described, so a small mesh size must therefore be used in the FE analyses.

The stress build-up and resulting crack patterns from the analysis model have been compared with laboratory results from testing of shrinking shotcrete. For the evaluation of the model behaviour, also results from tests with smaller scale cast concrete beams were used. Primarily, the appearance of shrinkage crack and crack patterns were studied and compared. The presented examples demonstrated that an endrestrained slab is prone to shrinkage induced cracking and will show one large crack due to absence of other restraints, while a fully restrained slab, bonding to the subsurface, will show multiple thinner cracks. This confirms previous experimental results and shows that the model therefore can be used in the design process of shotcrete linings to find critical sections with respect to thickness variations. It was here demonstrated that the topography and distribution of shotcrete thickness are the most important parameters for the formation of shrinkage cracks. Variation in bond strength and the appearance of sections with partial debonding also influence the result, which here also was demonstrated 
through comparison with results from shrinking concrete beams. A small local area of debonding, in an otherwise fully restrained shrinking beam or slab, can lead to formation of large cracks. This highlights the importance of a careful preparation of the rock surface prior to shotcreting to ensure good bond strength and no partial debonding. From a theoretical point of view, this also shows the importance of accurately describing the normal and shear bond strength between shotcrete and rock and how interaction between the two will affect the risk for bond failure.

The comparison between numerical analysis results and test results did not clearly show any evidence of positive effects on shrinkage reduction from glass fibre reinforcement. The previously presented test results did, however, indicate a delay in cracking in some cases which here was accounted for in the comparisons. It is possible that the fibres interact with the effect from the subsurface bond in distributing the cracking over many thinner cracks, which here was the case for a thicker slab with a relatively high amount of glass fibres added. For such a case, shrinkage cracks are to be expected in both main-axis directions over a rectangular shotcrete surface. However, the examples demonstrated that, also for fully restrained slabs, there can be cases with only few and wide cracks, as for slabs with end restraints only.

An interesting topic for further studies is to compare the accuracy in describing crack propagation between different material models. This should also include the variations in material properties as the young shotcrete hardens. Different growth rates for, for example, bond strength and stiffness may redistribute stresses that occur during shrinkage and thus affect possible shrinkage crack initiation. Using a damage criterion that considers interaction between normal and shear stresses will also increase the modelling accuracy, especially in the case of partial debonding. The precision of the modelling technique should be further tested and developed through further comparisons with laboratory and test results.

\section{Conflicts of Interest}

The authors declare that they have no conflicts of interest.

\section{Acknowledgments}

The work presented in this paper is part of a larger research project focusing on numerical simulations of irregular shotcrete and the interaction between shotcrete and hard rock. The project is sponsored by BeFo, the Rock Engineering Research Foundation, and their support is hereby greatly acknowledged. The authors are also grateful for the collaboration with Dr. Lars Elof Bryne, who carried out the experimental work addressed in this paper.

\section{References}

[1] J. Holmgren, "Shotcrete research and practice in Sweden a development over 35 years," in Shotcrete: Elements of a System, pp. 135-142, CRC Press/Balkema, Sydney, Australia, 2010.
[2] U. Nilsson, Structural behaviour of fibre reinforced sprayed concrete anchored in rock [Ph.D. thesis], KTH Royal Institute of Technology, Stockholm, Sweden, 2003.

[3] L. Malmgren and E. Nordlund, "Interaction of shotcrete with rock and rock bolts-A numerical study," International Journal of Rock Mechanics and Mining Sciences, vol. 45, no. 4, pp. 538553, 2008.

[4] F. Barpi and D. Peila, "Influence of the tunnel shape on shotcrete lining stresses," Computer-Aided Civil and Infrastructure Engineering, vol. 27, no. 4, pp. 260-275, 2012.

[5] L. Malmgren, E. Nordlund, and S. Rolund, "Adhesion strength and shrinkage of shotcrete," Tunnelling and Underground Space Technology, vol. 20, no. 1, pp. 33-48, 2005.

[6] J. Carlswärd, Shrinkage cracking of steel fibre reinforced self compacting concrete overlays: test methods and theoretical modelling [Ph.D. thesis], Luleå University of Technology, Luleå, Sweden, 2006.

[7] P. Groth, Fibre reinforced concrete [Ph.D. thesis], Luleå University of Technology, Luleå, Sweden, 2010.

[8] A. Ansell, "Investigation of shrinkage cracking in shotcrete on tunnel drains," Tunnelling and Underground Space Technology, vol. 25, no. 5, pp. 607-613, 2010.

[9] L. E. Bryne, Time dependent material properties of shotcrete for hard rock tunneling [Ph.D. thesis], KTH Royal Institute of Technology, Stockholm, Sweden, 2014.

[10] A. Sjölander, T. Gasch, A. Ansell, and R. Malm, "Shrinkage cracking of thin irregular shotcrete shells using multiphysics models," in Proceedings of the 9th International Conference on Fracture Mechanics of Concrete and Concrete Structures, Berkeley, Calif, USA, 2016.

[11] A. Sjölander, W. Bjureland, and A. Ansell, "On failure probability of thin irregular shotcrete shells," in Proceedings of ITAAITES World Tunnel Conference, Bergen, Norway, June 2017.

[12] A. Sjölander and A. Ansell, "Analysis of the interaction between rock and shotcrete for tunnel support," in Proceedings of 23th Nordic Concrete Research Symposium, Aalborg, Denmark, August 2017.

[13] B. Lagerblad, L. Fjällberg, and C. Vogt, "Shrinkage and durability of shotcrete," in Shotcrete: Elements of a System, pp. 173-180, CRC Press/Balkema, Sydney, Australia, 2010.

[14] E. S. Bernard, "Early-age load resistance of fibre reinforced shotcrete linings," Tunnelling and Underground Space Technology, vol. 23, no. 4, pp. 451-460, 2008.

[15] L. E. Bryne, A. Ansell, and J. Holmgren, "Shrinkage testing of end-restrained shotcrete on granite slabs," Magazine of Concrete Research, vol. 66, no. 17, pp. 859-869, 2014.

[16] L. Ahmed, Models for analysis of young cast and sprayed concrete subjected to impact-type loads [Ph.D. thesis], KTH Royal Institute of Technology, Stockholm, Sweden, 2015.

[17] L. E. Bryne, A. Ansell, and J. Holmgren, "Laboratory testing of early age bond strength of shotcrete on hard rock," Tunnelling and Underground Space Technology, vol. 41, no. 1, pp. 113-119, 2014.

[18] R. Jansson, Fire spalling of concrete: theoretical and experimental studies [Ph.D. thesis], KTH Royal Institute of Technology, Stockholm, Sweden, 2013.

[19] J. M. L. Reis and A. J. M. Ferreira, "Assessment of fracture properties of epoxy polymer concrete reinforced with short carbon and glass fibers," Construction and Building Materials, vol. 18, no. 7, pp. 523-528, 2004. 
[20] J. M. L. Reis, "Fracture and flexural characterization of natural fiber-reinforced polymer concrete," Construction and Building Materials, vol. 20, no. 9, pp. 673-678, 2006.

[21] I. Merta and E. K. Tschegg, "Fracture energy of natural fibre reinforced concrete," Construction and Building Materials, vol. 40, pp. 991-997, 2013.

[22] M. T. Kazemi, F. Fazileh, and M. A. Ebrahiminezhad, "Cohesive crack model and fracture energy of steel-fiber-reinforcedconcrete notched cylindrical specimens," Journal of Materials in Civil Engineering, vol. 19, no. 10, pp. 884-890, 2007.

[23] CEN, En 1488-3: Testing Sprayed Concrete Part 3: Flexural Strengths (First Peak, Ultimate and Residual) of Fibre Reinforced Beam Specimens, European Committee for Standardization, Brussels, Belgium, 2015.

[24] A. Hillerborg, M. Modéer, and P.-E. Petersson, "Analysis of crack formation and crack growth in concrete by means of fracture mechanics and finite elements," Cement and Concrete Research, vol. 6, no. 6, pp. 773-781, 1976.

[25] Fib, Fib Model Code for Concrete Structures 2010, Wiley-VCH, weinheim, Germany, 2013.

[26] Simulia, Abaqus 6.14 Online Documentation, Dassault Systeme, 2014.

[27] Altair, Hyper Works 13.0, Altair, 2014.

[28] J. Silfwerbrand, "Shear bond strength in repaired concrete structures," Materials and Structures, vol. 36, no. 260, pp. 419424, 2003.

[29] T. Hahn, "Bond strength of shotcrete against various rock surfaces," Tech. Rep. 55:1/83, BeFo, Stockholm, Sweden, 1983.

[30] D. Saiang, L. Malmgren, and E. Nordlund, "Laboratory tests on shotcrete-rock joints in direct shear, tension and compression," Rock Mechanics and Rock Engineering, vol. 38, no. 4, pp. 275297, 2005.

[31] T. Ellison, "Bond strength testing at Södra länken Stockholm," Tech. Rep., Besab, Gothenburg, Sweden, 2010.

[32] Z. A. Moradian, G. Ballivy, and P. Rivard, "Application of acoustic emission for monitoring shear behavior of bonded concrete-rock joints under direct shear test," Canadian Journal of Civil Engineering, vol. 39, no. 8, pp. 887-896, 2012. 


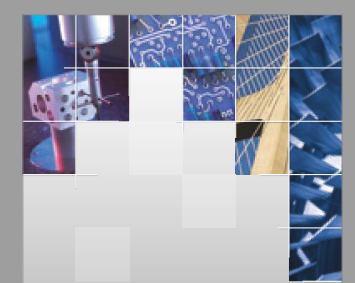

\section{Enfincering}
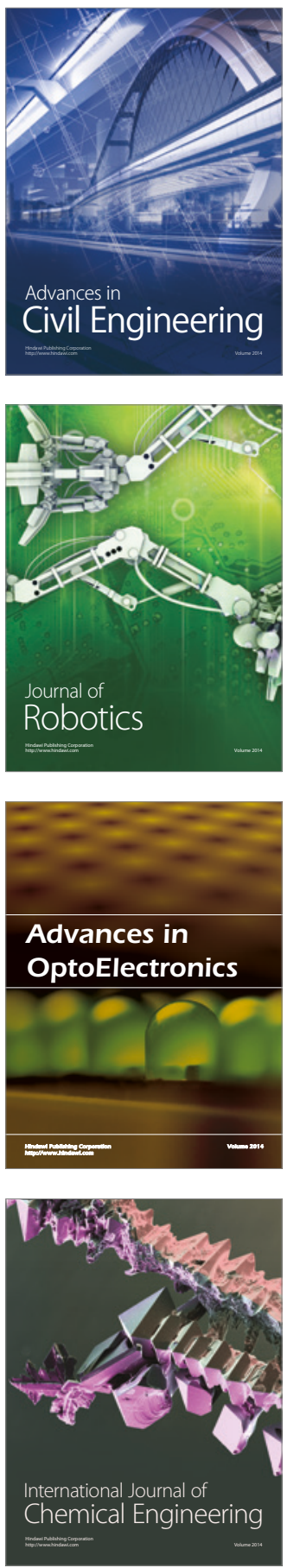

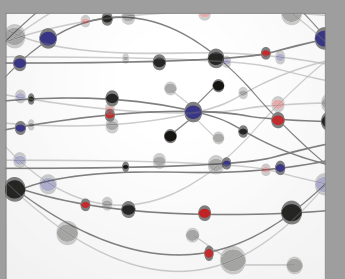

The Scientific World Journal

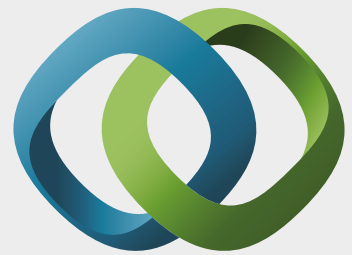

\section{Hindawi}

Submit your manuscripts at

https://www.hindawi.com
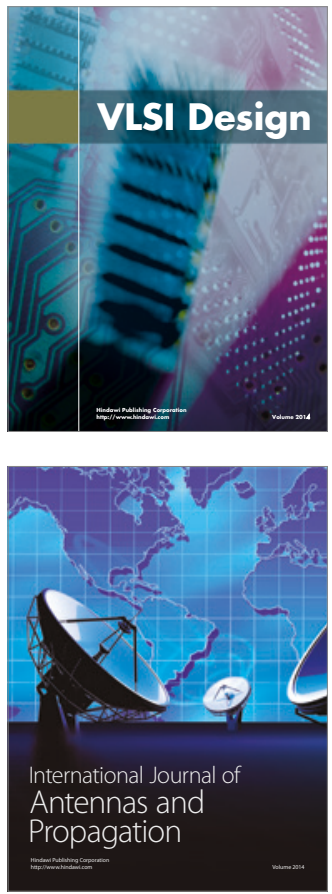

\section{Rotating}

Machinery
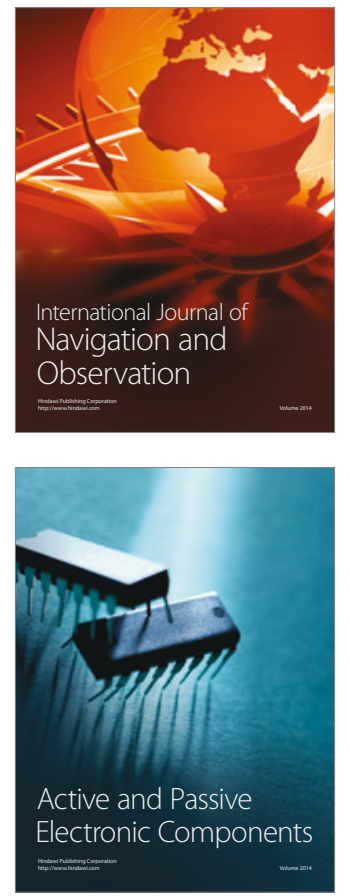
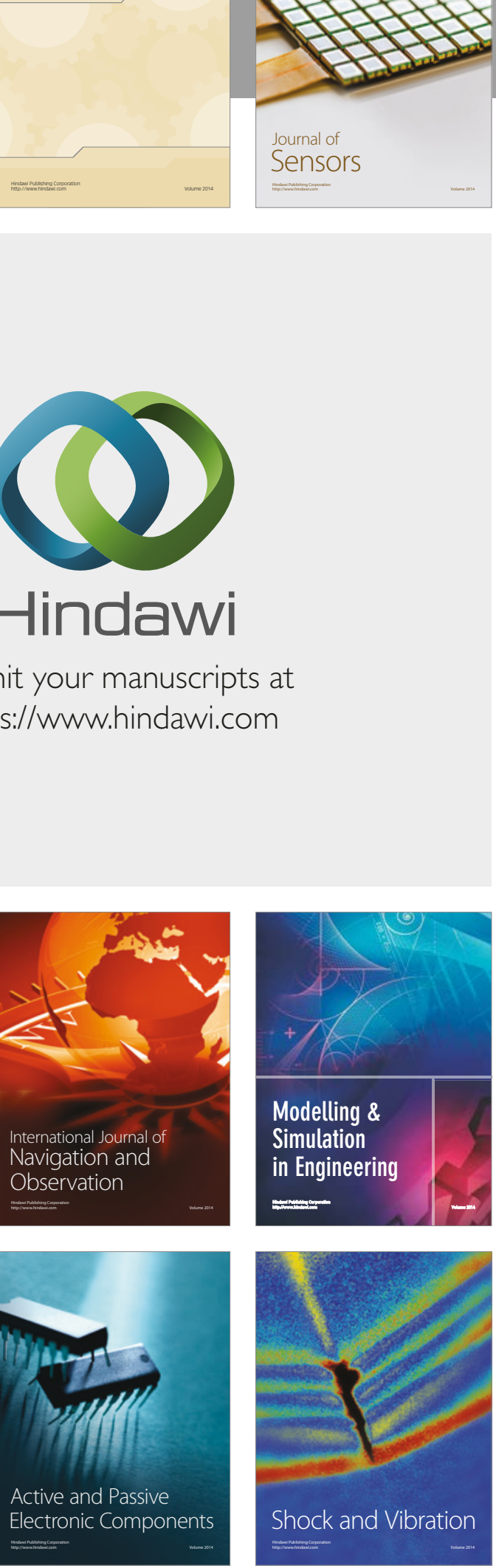
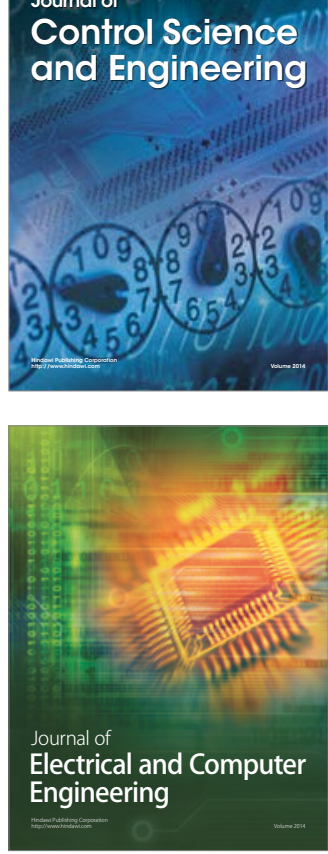

Distributed

Journal of

Control Science

and Engineering
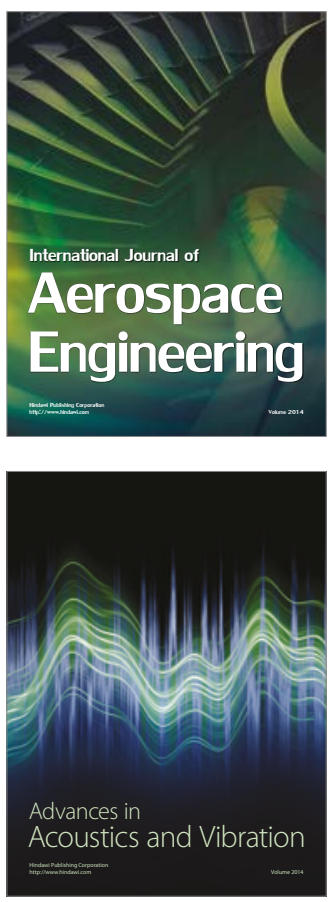

Sensor Networks 